\title{
Article
}

\section{Weather Factors Associated with Reduced Risk of Dengue Transmission in an Urbanized Tropical City}

\author{
Hao Gui ${ }^{1,2}$, Sylvia Gwee ${ }^{1,2}$, Jiayun Koh ${ }^{1,2}$ and Junxiong Pang 1,2,*(D) \\ 1 Saw Swee Hock School of Public Health, National University of Singapore and National University Health \\ System, 12 Science Drive 2, \#10-01, Singapore 117549, Singapore; ephgh@nus.edu.sg (H.G.); \\ ephsgxw@nus.edu.sg (S.G.); mskohjiayun@gmail.com (J.K.) \\ 2 Centre for Infectious Disease Epidemiology and Research, National University of Singapore, \\ 12 Science Drive 2, \#10-01, Singapore 117549, Singapore \\ * Correspondence: pangv@hotmail.com
}

Citation: Gui, H.; Gwee, S.; Koh, J.; Pang, J. Weather Factors Associated with Reduced Risk of Dengue Transmission in an Urbanized Tropical City. Int. J. Environ. Res. Public Health 2022, 19, 339. https:// doi.org/10.3390/ijerph19010339

Academic Editor: Paul B. Tchounwou

Received: 29 September 2021 Accepted: 24 December 2021 Published: 29 December 2021

Publisher's Note: MDPI stays neutral with regard to jurisdictional claims in published maps and institutional affiliations.

Copyright: (C) 2021 by the authors. Licensee MDPI, Basel, Switzerland. This article is an open access article distributed under the terms and conditions of the Creative Commons Attribution (CC BY) license (https:// creativecommons.org/licenses/by/ $4.0 /)$.

\begin{abstract}
This study assessed the impact of weather factors, including novel predictors-pollutant standards index (PSI) and wind speed—on dengue incidence in Singapore between 2012 and 2019. Autoregressive integrated moving average (ARIMA) model was fitted to explore the autocorrelation in time series and quasi-Poisson model with a distributed lag non-linear term (DLNM) was set up to assess any non-linear association between climatic factors and dengue incidence. In DLNM, a PSI level of up to 111 was positively associated with dengue incidence; incidence reduced as PSI level increased to 160. A slight rainfall increase of up to $7 \mathrm{~mm}$ per week gave rise to higher dengue risk. On the contrary, heavier rainfall was protective against dengue. An increase in mean temperature under around $28.0^{\circ} \mathrm{C}$ corresponded with increased dengue cases whereas the association became negative beyond $28.0^{\circ} \mathrm{C}$; the minimum temperature was significantly positively associated with dengue incidence at around $23-25^{\circ} \mathrm{C}$, and the relationship reversed when temperature exceed $27^{\circ} \mathrm{C}$. An overall positive association, albeit insignificant, was observed between maximum temperature and dengue incidence. Wind speed was associated with decreasing relative risk (RR). Beyond prevailing conclusions on temperature, this study observed that extremely poor air quality, high wind speed, minimum temperature $\geq 27^{\circ} \mathrm{C}$, and rainfall volume beyond $12 \mathrm{~mm}$ per week reduced the risk of dengue transmission in an urbanized tropical environment.
\end{abstract}

Keywords: dengue; air quality; wind speed; temperature; rainfall

\section{Introduction}

Dengue is a mosquito-borne viral disease that is endemic in tropical and subtropical regions. Globalization and global warming, however, have facilitated its expansion to nonendemic countries over the years [1,2]. An estimated 50 to 200 million dengue infections occur annually, with more than half the world at risk of infection [3]. The disease may escalate and cause dengue hemorrhagic fever (DHF) in a small minority, and the annual death toll from dengue lies between 20,000 and 25,000. Four antigenically distinct serotypes (DENV1/2/3/4) co-circulate globally, and DHF is more often associated with secondary infections [4].

The underlying causes of dengue epidemics in endemic countries are multifactorial [5] and are reflective of the interplay between host, vector, virus, and environment in disease transmission. Factors that drive epidemics include a change in predominant serotype [6,7], or lowered herd immunity due to waning immunity, and increased proportion of susceptible individuals accompanying population replacement [8,9]. Climatic factors are also integral to dengue transmission, as reflected by the seasonal nature of the disease $[10,11]$.

Aedes aegypti (Ae. aegypti), the more efficient vector of dengue virus than Aedes albopictus, is adapted to peri-domestic environments [12,13]. In urban settings, outdoors breeding of Ae. aegypti in rainwater accumulating containers gives an indication of how 
climatic factors support environment factors that influence vector growth $[14,15]$. There is much evidence that meteorological factors including temperature, rainfall, humidity, and air quality influence vector growth and distribution both directly and indirectly. Studies have found that a temperature rise of up to $34{ }^{\circ} \mathrm{C}$ increases all stages of Ae. aegypti developmental rates, resulting in population growth [16]. Increased dengue transmission under warmer temperatures can arise from faster viral replication within the vector, shortened extrinsic incubation period, and increased feeding rate of Ae. aegypti [16-18]. Humidity also increases viral propagation and hatch percentage of Ae. aegypti eggs $[19,20]$. Human practices coupled with climatic factors, such as water storage in dry climates, can encourage mosquito productivity, and dengue transmission [21]. This is exemplified by Schmidt et al.'s findings of higher dengue risk in rural areas characterized by the absence of tap water supply [22].

In general, the significant effect of warmer temperatures on increased dengue rates is largely consistent across studies, while the role of humidity, air quality, rainfall, and haze on dengue transmission is not clear and less often studied $[6,23,24]$. A comprehensive understanding of how meteorological factors influence vectors and humans is crucial for disease forecasting and control. Additionally, it has been recognized that predictive models for dengue transmission need to account for the interaction between climatic, host-vector specific, and viral factors.

Singapore is a tropical country where dengue resurgence typically occurs in a 5-6-year cycle, but the last decade has seen dengue escalate to record numbers $[7,25]$. Despite aggressive vector control programs and public awareness campaigns, dengue cases surpassed the tens of thousands between 2013 and 2019 [7,26,27]. Another strategy adopted by the Singapore government has been to publicize data on the real-time distribution of cases and hotspots as part of timely alerts to the community $[7,25,28]$. Nonetheless, evidence has shown that vector control is the most effective means to reduce dengue transmission [9], and it is envisaged that predictive surveillance and the targeted response would be an efficient long-term strategy.

Hence, this study aims to assess the association between multiple weather factors and dengue incidence in Singapore between 2012 and 2019, as well as examine the roles of less well-characterized weather variables including air quality and wind speed. This would help inform dengue predictive models in the region and guide targeted disease control efforts.

\section{Materials and Methods}

\subsection{Data Collection}

Weekly notified dengue cases in Singapore from 1 January 2012 to 25 August 2019 were collected from the Weekly Infectious Diseases Bulletin published by the Ministry of Health [28]. Daily weather data collected include the mean, maximum and minimum temperature $\left({ }^{\circ} \mathrm{C}\right)$, total rainfall $(\mathrm{mm})$, mean wind speed $(\mathrm{km} / \mathrm{h})$, and pollutant standard index (PSI), all of which were obtained from open sources released by the National Environment Agency [29]. The data were collected across meteorological stations evenly distributed over Singapore. City-wide data points were aggregated by averaging across all stations while all daily figures were averaged across each reporting week to obtain weekly-representative data such that it was on a consistent scale with the dengue cases provided by the Ministry of Health. The total population data were based on the mid-year human population of the respective year from the Singapore Department of Statistics [30].

\subsection{Statistical Analysis}

\subsubsection{Autoregressive Integrated Moving Average (ARIMA) Model}

Autoregressive integrated moving average (ARIMA) is a class of models that "explains" a given time series based on historical values. For initial analysis, the univariate ARIMA model was built to capture the time structure of dengue cases. Weather variables 
with appropriate lags were added as exogenous variables to improve the model. The equation used for ARMA ( $p, q)$ model is as follows:

$$
y_{t}=c+a_{1} y_{t-1}+\ldots+a_{p} y_{t-p}+u_{t}+m_{1} u_{t-1}+\ldots+m_{q} u_{t-q}
$$

where $y_{t}$ is the target time series value at time $t ; c$ is constant; $u_{t}, u_{t-1}, \ldots, u_{t-q}$ are white noise error terms; $a_{i}(i=1,2 \ldots p)$ and $m_{i}(i=1,2 \ldots q)$ are corresponding parameters.

Since the time-series graph (Figure 1 ) indicated a clear long-term trend and nonstationary trait, first-differencing of the data was conducted to build the ARIMA model. Weekly dengue cases numbers were then subjected to natural log transformation to stabilize the variance. The seasonal ARIMA model was also investigated but results were placed in the supplementary due to drawback of weekly data-the seasonal period is not a common number usually representing one year (52 weeks).

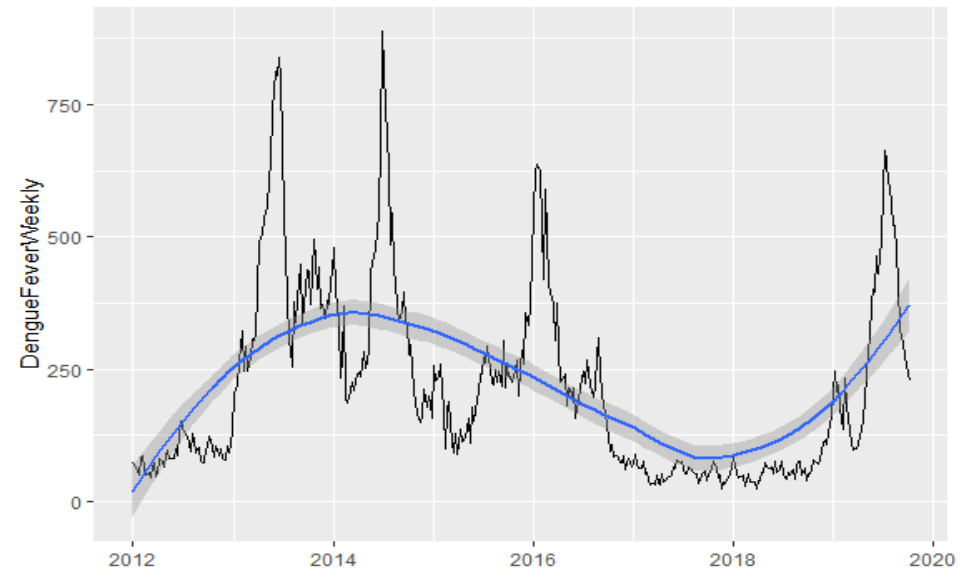

Figure 1. Weekly number of dengue fever cases with smoothed line.

The cross-correlation function (CCF) graphs showcase all-weather factor correlations with weekly dengue incidence while accounting for lagged effects, at a significance level of 0.05. Due to the autocorrelation of both time series, inference of coefficient's correlation may not be robust and pre-whitening technique was applied to circumvent the issue [31] Pearson correlations were considered for a linear relationship. Of all the models tested, an $\operatorname{ARIMA}(1,1,0)$ model was found to best fit our data. The equation $\operatorname{ARIMA}(1,1,0)$ with exogenous variable is as follows:

$$
y_{t}^{\prime}=\log \left(y_{t}\right), y_{t}^{\prime}=u_{t}+\alpha_{2} x_{t-l}, \nabla u_{t}=\alpha_{1} \nabla u_{t-1}+w_{t}
$$

where $\alpha_{1}, \alpha_{2}$ are coefficients of the autoregressive term and exogenous variables, respectively; $x_{t-l}$ refers to exogenous weather values with $l$ weeks lag effect; $u_{t}$ refers to the residual of regression; $\nabla u_{t}$ is the residual with one-order differencing; $w_{t}$ is the white noise error term. Only univariate weather factor models were constructed here.

\subsubsection{Distributed Lag Non-Linear Model}

Recognizing that relationships between weather and dengue are not simply linear in practice, non-linear associations were also explored using a distributed lag non-linear model (DLNM) [32]. DLNM is an advanced statistical method developed to simultaneously estimate the nonlinear and delayed effects of the concerning exposure on response. The cross-basis function describes a two-dimensional relationship along the dimensions of factor and distributed lag is the core of DLNM implementation. Compared to other methods, DLNM has three advantages [33]. First, beyond the usual exposure-response relationship, exposure-lag-response defined by Antonio Gasparrini introduced additional temporal dimensions needed to express the association. Second, nonlinear dependencies capture more complicated patterns than linear exposure-response relationships. Third, DLNM has 
been evaluated and confirmed to offer a well-grounded performance regarding complex estimation routines, as well as a comprehensive scheme for interpretation.

The number of weekly dengue cases was assumed to follow an over-dispersed Poisson distribution [34]. Thus, quasi-Poisson regression coupled with DLNM cross-basis was considered. Univariate exposure analysis was conducted first for simplicity. The model equation in this study is [19] as follows:

$\log \left(E\left(y_{t}\right)\right)=\beta_{0}+\beta_{1} \log \left(y_{t-1}\right)+\beta_{2} \log \left(y_{t-2}\right)+s_{1}\left(x_{t, j}, l_{j}, \delta_{1}, \delta_{2}, \Phi_{j}\right)+s_{2}(t, \delta, \Psi)+\log \left(N_{t}\right)$

$y_{t}$ is the number of dengue cases at week $t$, while $\beta_{1}$ and $\beta_{2}$ are the coefficients of the autoregression terms - two autocorrelation terms were introduced into models as the ARIMA model and residual analysis indicated that dengue cases from the past two weeks would be significantly correlated with a current number of cases. $s_{1}\left(x_{t, j}, l_{j}, \delta_{1}, \delta_{2}, \Phi_{j}\right)$ is the cross-basis of distributed lag non-linear terms with $x_{t, j}$ representing a single weather factor at week $t$, and $l_{j}$ representing the maximum lag number. A natural cubic spline (ns) smoothing method with $\delta_{1}, \delta_{2}$ degree of freedom (df) was used to describe the non-linear effect in both weather factor and lag time, respectively, with $\Phi_{j}$ denoting corresponding coefficients. $s_{2}(t, \delta, \Psi)$ is another natural cubic spline term to describe the long-term trend and seasonality of dengue cases time series, with $\delta, \Psi$ representing degree freedom and corresponding coefficients. Here, the degree freedom is assigned to be 1 per year, therefore the $\delta$ equals to duration of the study period in years (approximately 8 years). $\log \left(N_{t}\right)$ is the offset term that considers the effect of differences in Singapore's mid-year population. Notation "log" in Equation (2) represents the natural log transformation.

Quasi Akaike's information criterion (QAIC) was applied to evaluate the goodness of fit.

$$
Q A I C=-2 \mathcal{L}(\hat{\Theta})+2 \hat{\phi} k
$$

As shown in the equation above, $\mathcal{L}(\hat{\Theta})$ is the log-likelihood of estimated parameters, $\hat{\phi}$ is the estimated over-dispersion parameter and $\mathrm{k}$ is the number of parameters. Instead of using the same degree of freedom for all-weather factors, we applied the grid search method to derive the best degree of freedom for each factor, which satisfied both parsimony and fit accuracy based on QAIC. Thereafter, values between 2-6 were selected for $\delta_{1}$ term in Equation (2), while values between 3-5 were selected for $\delta_{2}$. The selected values for maximum lag numbers $l_{j}$ in Equation (2) was 0-16 weeks (i.e., roughly four months) [35,36].

Relative risk (RR) with $95 \%$ confidence intervals $(\mathrm{CI})$ was selected to be the measure of effect. The exposure-response relationship estimated by DLNM was visualized with graphical representations, including 3D graphs, contour graphs, sliced graphs, and overall effect graphs [32]. 3D and contour graphs display the variation of RR along with 2dimensional basis exposure and lag. Sliced graphs extract one slice from 3D graphs to emphasize relationships at one specific exposure value or lag. Overall effect graphs were used to measure the overall performance of association by summing up the RR of each lag. The median of each climatic variable was used as the reference, in line with the aim of examining non-linear trends with possible threshold effects.

\subsubsection{Sensitivity Analysis}

In addition, sensitivity analysis was performed by changing the degree of freedom (df) of natural cubic spline terms to check the robustness of the model. The degree freedom of time $(\delta)$ was changed by setting 2 and $3 \mathrm{df}$ per year to interpret the potential seasonality pattern. Moreover, we replaced the natural cubic spline with a polynomial function with different degrees to depict the nonlinear association between the weather factor and dengue incidence. The benchmark of the judgement was based on overall effect graphs.

All statistical analyses were performed on R software (version 3.6.1; R Foundation for Statistical Computing, Vienna, Austria.), and included the use of package "dlnm", version 2.3.9 [37]. 


\section{Results}

\subsection{Epidemiological Characteristics of Epidemics between 2012 and 2019 in Singapore}

Between January 2012 and August 2019, there were a total of five major dengue epidemics with the incidence above 100 per 100,000 in Singapore [38]. The time-series data of dengue case trend over the study period illustrates epidemics characterized by peaks in 2013, 2014, 2015, 2016, and 2019 (Figure 1). The average weekly number of dengue infections was 217.02. Generally, there were small variations in weekly temperature and wind speed, whereas weekly rainfall and PSI varied across a wider range (Table 1).

Table 1. Descriptive summary of weekly dengue cases and weather conditions in Singapore during 2012-2019.

\begin{tabular}{|c|c|c|c|c|c|c|c|c|}
\hline Variable & Mean & Std & Min & P25 & Median & P75 & Max & Hist \\
\hline DengueFeverWeekly & 217.02 & 179.72 & 24.00 & 73.75 & 170.50 & 303.75 & 891.00 & \\
\hline Rainfalltotal & 6.37 & 4.67 & 0.00 & 2.72 & 5.54 & 8.93 & 25.36 & \\
\hline Meantemperature & 27.97 & 0.86 & 25.04 & 27.38 & 28.01 & 28.51 & 30.02 & \\
\hline Maxtemperature & 31.79 & 0.97 & 27.89 & 31.25 & 31.84 & 32.42 & 34.19 & \\
\hline Mintemperature & 25.25 & 0.82 & 23.17 & 24.63 & 25.14 & 25.79 & 27.70 & \\
\hline PSI & 46.78 & 17.15 & 16.45 & 35.29 & 48.22 & 54.74 & 165.85 & \\
\hline Windspeed & 7.88 & 1.74 & 4.99 & 6.61 & 7.52 & 8.75 & 14.89 & \\
\hline
\end{tabular}

P25—25th percentile; P75—75th percentile: PSI—Pollutant Standards Index.

The 2013 epidemic holds the current national record for the highest number of dengue cases in a year, where the dengue incidence was 22,170 cases (404.9 cases per 100,000 population annually) and dengue 1 serotype was the predominant serotype (Table S1). Thereafter, high incidence levels continued to be seen in the 2014 epidemic, which became Singapore's second-largest outbreak within a year-the dengue incidence was 18,326 cases (325.6 cases per 100,000 population annually), with dengue 1 serotype as the predominant serotype. The 2015 epidemic was comparatively mild, with dengue incidence at 11,294 cases (196.1 cases per 100,000 population annually) and was predominated by serotype 2 . Subsequently, the 2016 epidemic saw a dengue incidence of 13,085 cases (229.1 cases per 100,000 population annually) and was predominated by dengue 2 serotype. After low dengue activity levels for a couple of years, the 2019 epidemic became the third-biggest dengue outbreak recorded nationally with a dengue incidence of 16,100 cases (282.3 cases per 100,000 population annually), and dengue 2 and 3 serotypes taking over as the co-predominant serotypes $[30,39,40]$.

\subsection{Linear Relationship with Weather Factors in Cross-Correlation and ARIMA Modelling}

Pearson's cross-correlation coefficients for each climatic factor after pre-whitening are shown in Table 2 and cross-correlation graphs can be seen in Figure S1. In general, pollutant standard index (PSI) five weeks and seven weeks before the dengue onset was significantly and negatively correlated with dengue cases. In addition, the mean wind speed was found to have a significant negative correlation with five-week delayed dengue cases. As for temperature indicators, mean temperature (lag effect after 1, 2, 11 weeks), maximum temperature (lag effect after 11,13, 14 weeks), and minimum temperature (lag effect after 1, 2, 3 weeks) were positively correlated with weekly dengue cases. No significant linear correlation was observed between rainfall and dengue incidence in Singapore. 
Table 2. Cross-correlation analysis and ARIMA modeling of meteorological factors to dengue incidence.

\begin{tabular}{|c|c|c|c|c|c|}
\hline Meteorological Factor & Lag of Week & $\begin{array}{l}\text { Cross Correlation } \\
\text { Coefficient }\end{array}$ & $\begin{array}{l}\text { Autoregressive } \\
\text { Coefficient } \alpha_{1} \\
(p \text {-Value })\end{array}$ & $\begin{array}{c}\text { Coefficients of } \\
\text { Exogenous Variable } \\
\alpha_{2}(p \text {-Value })\end{array}$ & $\begin{array}{c}\text { Akaïke } \\
\text { Information } \\
\text { Criterion (AIC) }\end{array}$ \\
\hline \multirow{3}{*}{ PSI } & 5 & -0.111 & $-0.2128(<0.001)^{* * *}$ & $-0.0020(0.043) *$ & -133.68 \\
\hline & 7 & -0.115 & $-0.2053(<0.001)^{* * *}$ & $-0.0020(0.0375) *$ & -133.91 \\
\hline & 1 & 0.115 & $-0.2121(<0.001)^{* * *}$ & $0.0296(0.0452) *$ & -131.67 \\
\hline \multirow{4}{*}{ Mean temperature $\left({ }^{\circ} \mathrm{C}\right)$} & 2 & 0.100 & $-0.2175(<0.001)^{* * *}$ & $0.0257(0.0854)$ & -130.61 \\
\hline & 11 & 0.118 & $-0.1970(<0.001)^{* * *}$ & $0.0318(0.0299)$ * & -132.37 \\
\hline & 11 & 0.155 & $-0.1995(<0.001)^{* * *}$ & $0.0358(0.0013)$ * & -143.4 \\
\hline & 13 & 0.110 & $-0.2045(<0.001)^{* * *}$ & $0.0031(0.7838)$ & -133.1 \\
\hline \multirow[t]{3}{*}{ Maximum temperature $\left({ }^{\circ} \mathrm{C}\right)$} & 14 & 0.123 & $-0.2115(<0.001)^{* * *}$ & $0.0164(0.1421)$ & -135.19 \\
\hline & 1 & 0.126 & $-0.2024(<0.001)^{* * *}$ & $0.0192(0.1811)$ & -126.77 \\
\hline & 2 & 0.114 & $-0.2064(<0.001)^{* * *}$ & $0.0167(0.2471)$ & -126.32 \\
\hline Minimum temperature $\left({ }^{\circ} \mathrm{C}\right)$ & 3 & 0.103 & $-0.2085(<0.001)^{* * *}$ & $0.0212(0.1413)$ & -127.15 \\
\hline Wind speed $(\mathrm{km} / \mathrm{h})$ & 5 & -0.124 & $-0.2108(<0.001)^{* * *}$ & $-0.0330(<0.001)^{* * *}$ & -146.44 \\
\hline Total rainfall (mm) & NS & NS & - & - & \\
\hline
\end{tabular}

Note: $\alpha_{1}$ is the coefficient of autoregressive term and $\alpha_{2}$ is the coefficient of exogenous weather variables in Equation (2); abbreviations: NS—not significant; * weakly significant; ${ }^{* * *}$ highly significant; PSI-Pollutant Standards Index.

Since a significant autocorrelation coefficient was found at a lag time of 1 week as indicated by the autocorrelation graph (Figure S2c), ARIMA $(1,1,0)$ with first-order differencing and one autoregressive term was selected as the best model to describe the trend and autoregressive parameters of the dengue time series. Residual diagnostics were conducted to assess model appropriateness, including the use of Ljung-Box tests $(p$-value $=0.3686)$ (Figure S3). The Akaike information criterion (AIC) of ARIMA $(1,1,0)$ was -128.47 .

Using univariate ARIMA models with covariates derived from significant crosscorrelations, the following factors were found to be significantly associated with dengue incidence: 5-week and 7-week time lag effect of PSI, 1-week and 11-week time lag effect of mean temperature, an 11-week time lag effect of maximum temperature and a 5-week time lag effect of mean wind speed (Table 2). Among the above significant covariates, PSI and mean wind speed showed protective effects from dengue cases, while others displayed positive effects. All models with statistically significant exogenous variables had lower AIC than simple ARIMA $(1,1,0)$ with no exogenous variable, which indicates an improvement in the fitting. The insignificance of covariates suggested by cross-correlation might be attributed to a $5 \%$ confidence level, which implies a $5 \%$ possibility of wrong signals.

\subsection{Non-Linear Relationship with Weather Factors in Cross-Correlation and DLNM}

For the quasi-Poisson model with distributed lag non-linear cross-basis terms, parameter settings with optimal fitting performance (the smallest $Q A I C$ ) were chosen. The choice of degree of freedom, parameters, and corresponding QAIC of each weather factor are shown in Table S2. The models in the univariate analysis included the effect on dengue cases by allowing for PSI (lag 0-16 weeks), total rainfall (lag 0-15 weeks), mean temperature (lag 0-16 weeks), maximum temperature (lag 0-16 weeks) and wind speed (lag 0-5 weeks), respectively. Autocorrelation of residuals was tested to ensure the absence of autocorrelation and the assumption of overdispersion was checked (Figure S4), justifying the use of quasi-Poisson regression. The fitted number of dengue cases predicted by our models mirrored the observed trend of dengue cases closely as seen in Figure 2. The graphical output of dengue DLNM modeling for each climatic variable is described in the following subsections. Additionally, we also conducted predictive models using 2012-2018 data as trial data, and 2019 data as test data. Details of the predictive models and their performance are detailed in the supplementary material (Table S3, Figures S5-S11). 
colour — Fitted Dengue Cases — Weekly Dengue Fever Cases

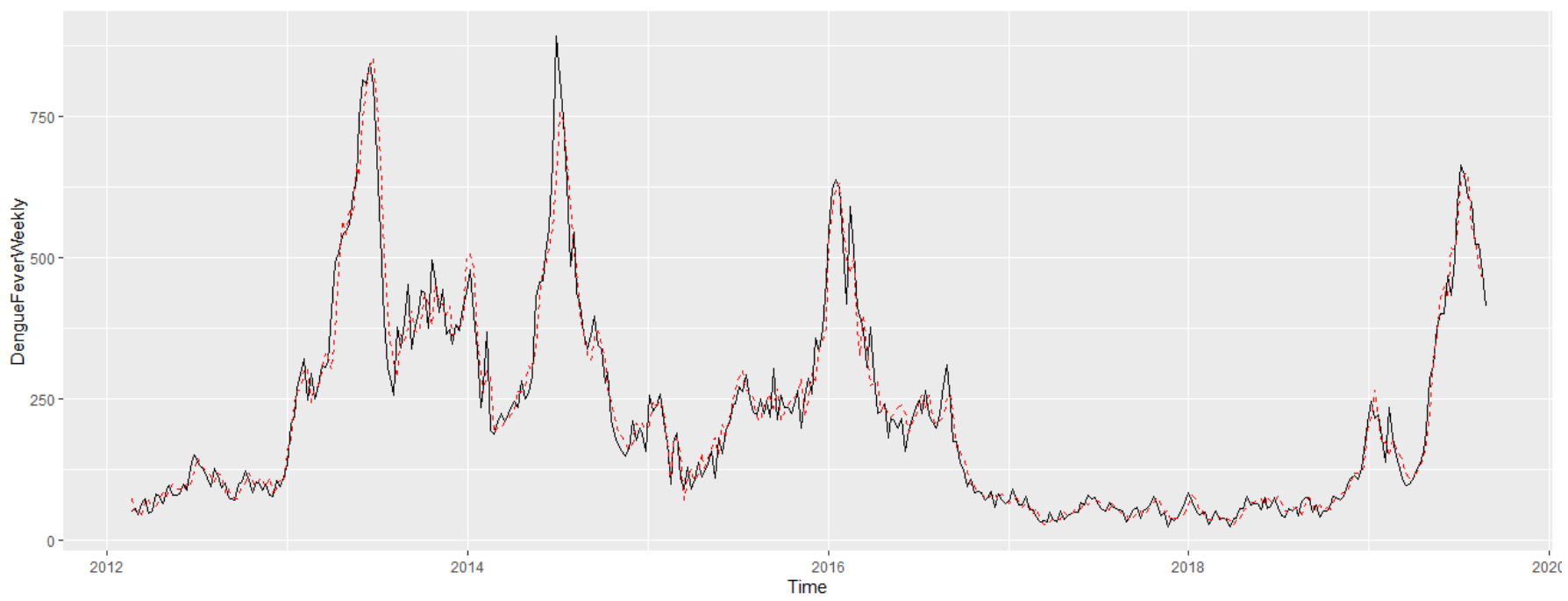

Figure 2. The estimated number of dengue cases (DLNM with wind speed) juxtaposed against the original dengue time series.

\subsubsection{Effect of PSI}

With a weekly PSI median of 48.22 as a reference, visualization of DLNM model output with the 3D graph and contour graph (Figure 3a,b) showed that the RR of dengue was generally higher when PSI (1) reached around 60-140 in the same week (lag0), and (2) was around 60-120 with a lag time of approximately $6-13$ weeks. On the contrary, RR of dengue was lower when PSI (1) exceeded approximately 140 regardless of any lag time, and (2) was within 60-140 with a lag time around 2-4 weeks.

The sliced graph for PSI at lag 7 (Figure 3c) indicated that increased PSI between 15 and 106 was associated with increased RR of dengue (RR at PSI of 106: 1.041, 95\% CI: 1.016, 1.066), and PSI beyond 106 was associated with dengue reduction (RR at PSI 160: 0.811, $95 \%$ CI: 0.725, 0.906). While the lag-response association differed across different PSI levels (Figure 3d), a consistent protective effect was observed across high PSI levels beyond 100 between the lag time of $0-2$ weeks.

The overall effects graph (Figure 3e) exhibited a similar trend as the sliced graphs at lag 7. A PSI level of up to 111 was positively associated with dengue incidence (RR at PSI 111: 1.339, 95\% CI: 1.020, 1.757), while the subsequent increase in PSI level to 160 was associated with a reduction in dengue incidence (RR at PSI 160: 0.116, 95\% CI: $0.031,0.442$ ).

\subsubsection{Effect of Rainfall}

The median of weekly total rainfall $(5.54 \mathrm{~mm})$ was taken as the reference. The 3D and contour graphs (Figure $4 a, b$ ) demonstrated the same fluctuation between positive and negative associations between exposure and response across all lags. Although the sliced graphs at lag 4 and lag 14 had similar curves, we observed slightly different confidence intervals, which suggested that rainfall with a 4-week lag time had a more significant positive effect on dengue incidence when the volume of total rainfall was low whereas rainfall with 14-week lag time had a more significant negative effect when the volume of total rainfall was relatively higher (Figure 4c). The overall effect graph showed a similar trend as with the sliced graphs, with rainfall of $7 \mathrm{~mm}$ per week associated with increased dengue incidence (Rainfall: 7 mm, RR: 1.21, 95\% CI: 1.06-1.38) (Figure 4d). On the contrary, heavier rainfall had an increasing "protective" effect against dengue, with RR: 0.45, 95\% CI: $0.29-0.72$ at rainfall level $12 \mathrm{~mm}$ per week and RR: $0.17,95 \%$ CI: $0.06-0.50$ at rainfall level $22 \mathrm{~mm}$ per week. An increased RR, albeit insignificant, was observed at rainfall levels of $15-18 \mathrm{~mm}$, indicating a higher risk of dengue at this interval compared to the reference. 

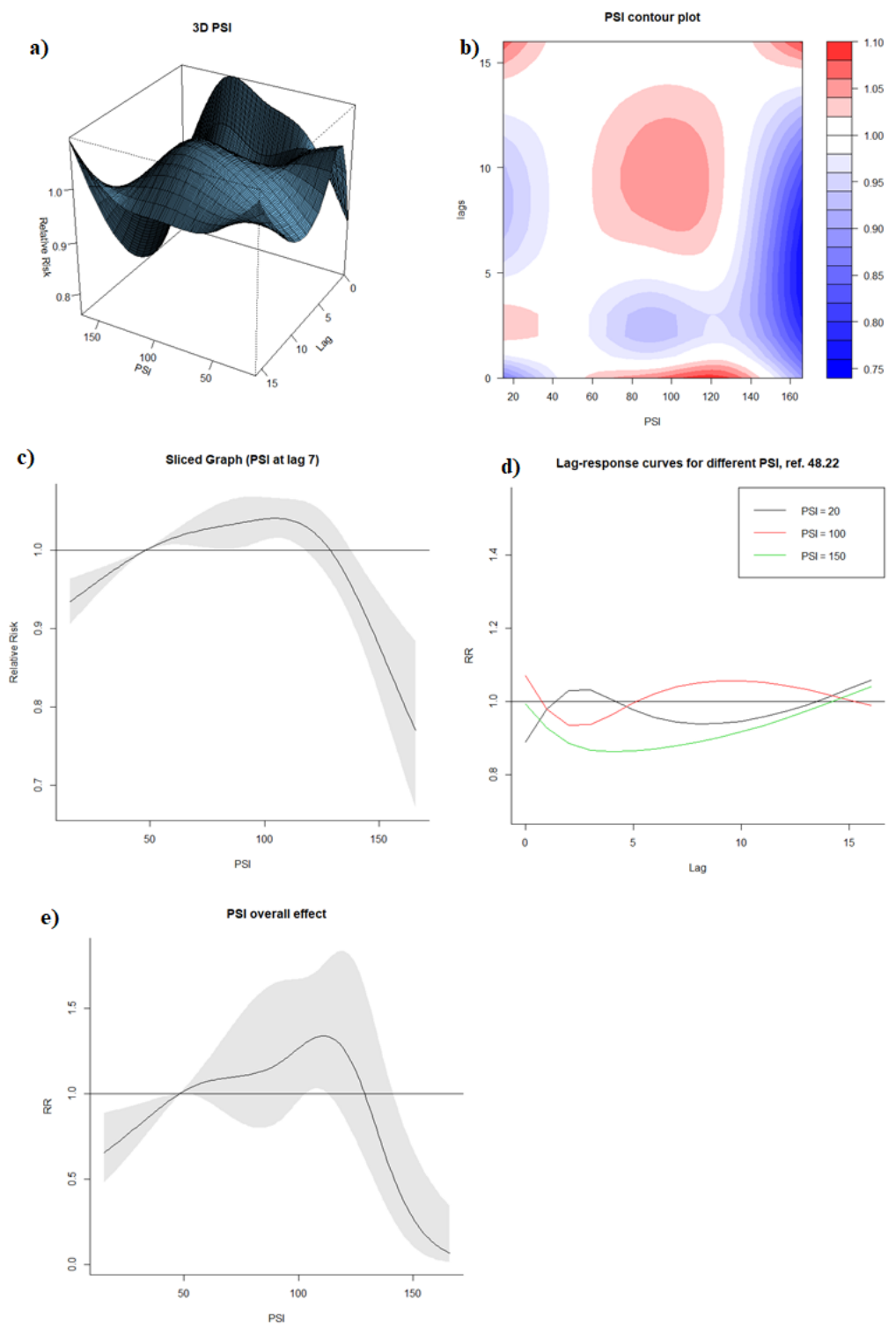

Figure 3. (a) 3D graph of PSI-lag-dengue association; (b) contour graph of PSI-lag-dengue association; (c) sliced graph of PSI-dengue association at lag 7; (d) sliced graph of Lag-response association at PSI level of 20, 100, 150; (e) overall effect graph of PSI-dengue association.

\subsubsection{Effect of Temperature}

The median of weekly mean, maximum and minimum temperatures were $28.0^{\circ} \mathrm{C}$, $31.8^{\circ} \mathrm{C}$ and $25.1^{\circ} \mathrm{C}$, respectively. From the 3D and contour graphs (Figure $5 \mathrm{a}, \mathrm{b}$ ), all three types of temperature showcased similar behavior in exposure-lag-response relationship. Each of them presented a different temperature-dengue correlation at each lag. Lags 1 and 5 were selected as the benchmark to illustrate the variation of association at different lags. The $\mathrm{RR}$ increased when mean, maximum and minimum temperatures increased with one-week lag. Such findings correspond with our conclusions from linear ARIMA model whereby there is a general positive association between temperature and incidence at around lag 1. On the other hand, the RR decreased once temperatures reached a higher level than their respective references at lag 5 (Figure $5 \mathrm{c}-\mathrm{e}$ ). Lag-response association, holding the temperature constant, behaved similarly in all three types of temperature (Figure $5 \mathrm{c}-\mathrm{e}$ ). At low temperatures (mean temperature $26{ }^{\circ} \mathrm{C}$, maximum temperature $29^{\circ} \mathrm{C}$, minimum temperature $23^{\circ} \mathrm{C}$ ), we observed a general positive association between dengue cases and every one-week increase in lag numbers despite of statistical insignificance. Prominent "harvesting" effects were observed when the mean, maximum and minimum temperatures 
were relatively high $\left(29^{\circ} \mathrm{C}, 33^{\circ} \mathrm{C}, 27^{\circ} \mathrm{C}\right)$ - a period of excess RR (lag 1) is followed by a negative estimate at longer lags (lag 1-4). In terms of overall effect (Figure $5 \mathrm{f}$ ), increase in mean temperature under around $28.0^{\circ} \mathrm{C}$ corresponded with increased dengue cases whereas the association became negative beyond $28.0^{\circ} \mathrm{C}$ (results were not statistically significant). Similarly, minimum temperature was significantly positively associated with dengue incidence at a lower temperature range of around $23-25^{\circ} \mathrm{C}$, and the relationship reversed with RR significantly reduced when temperature goes beyond $27^{\circ} \mathrm{C}$ (RR: 0.70 , $95 \%$ CI: $0.56,0.88)$. An overall positive association that was not statistically significant was observed between maximum temperature and dengue incidence.
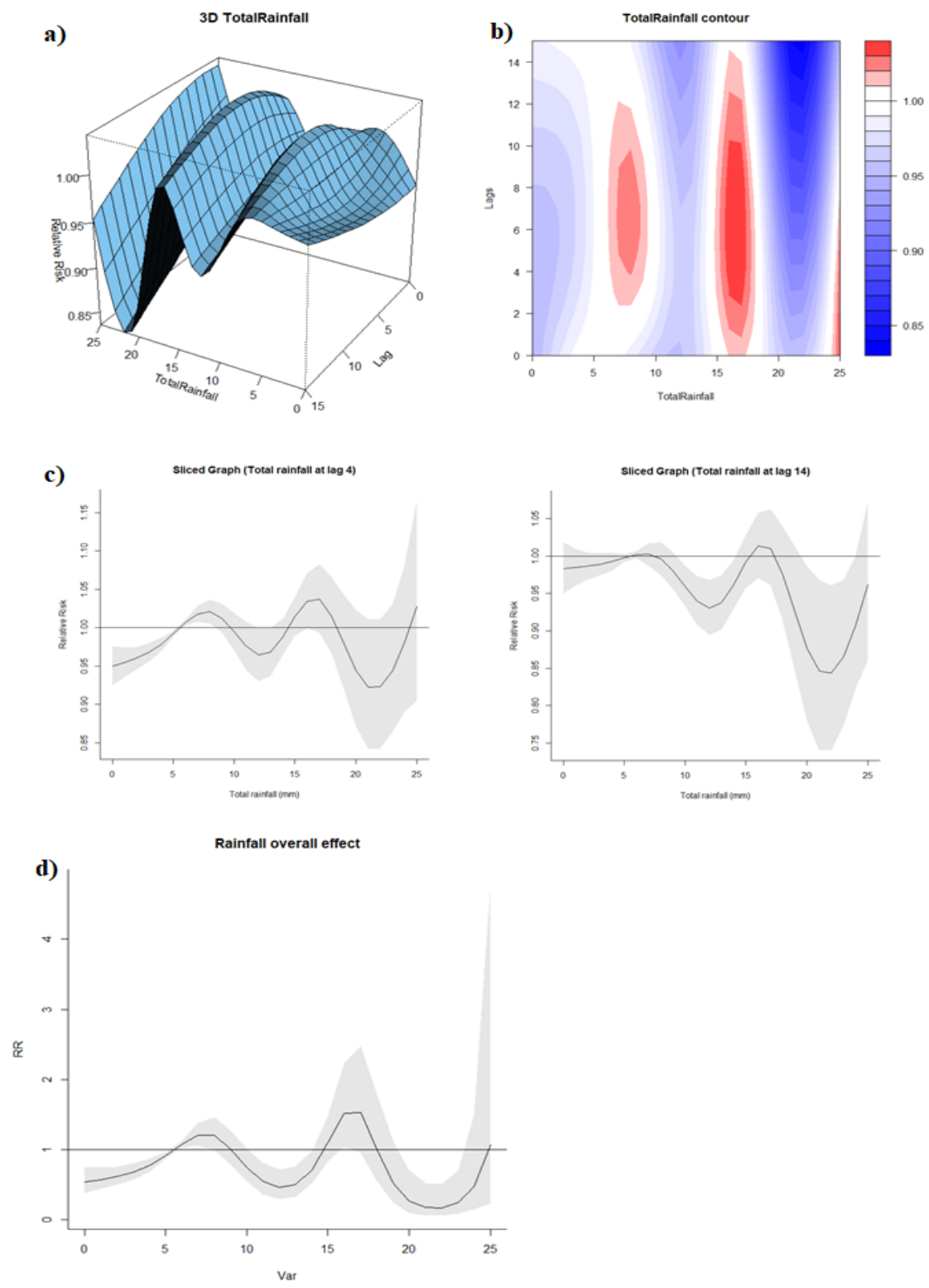

Figure 4. (a) 3D graph of rainfall-lag-dengue association; (b) contour graph of rainfall-lag-dengue association; (c) sliced graph of rainfall-dengue association at lag 4 and 11; (d) overall effect graph of rainfall-dengue association. 

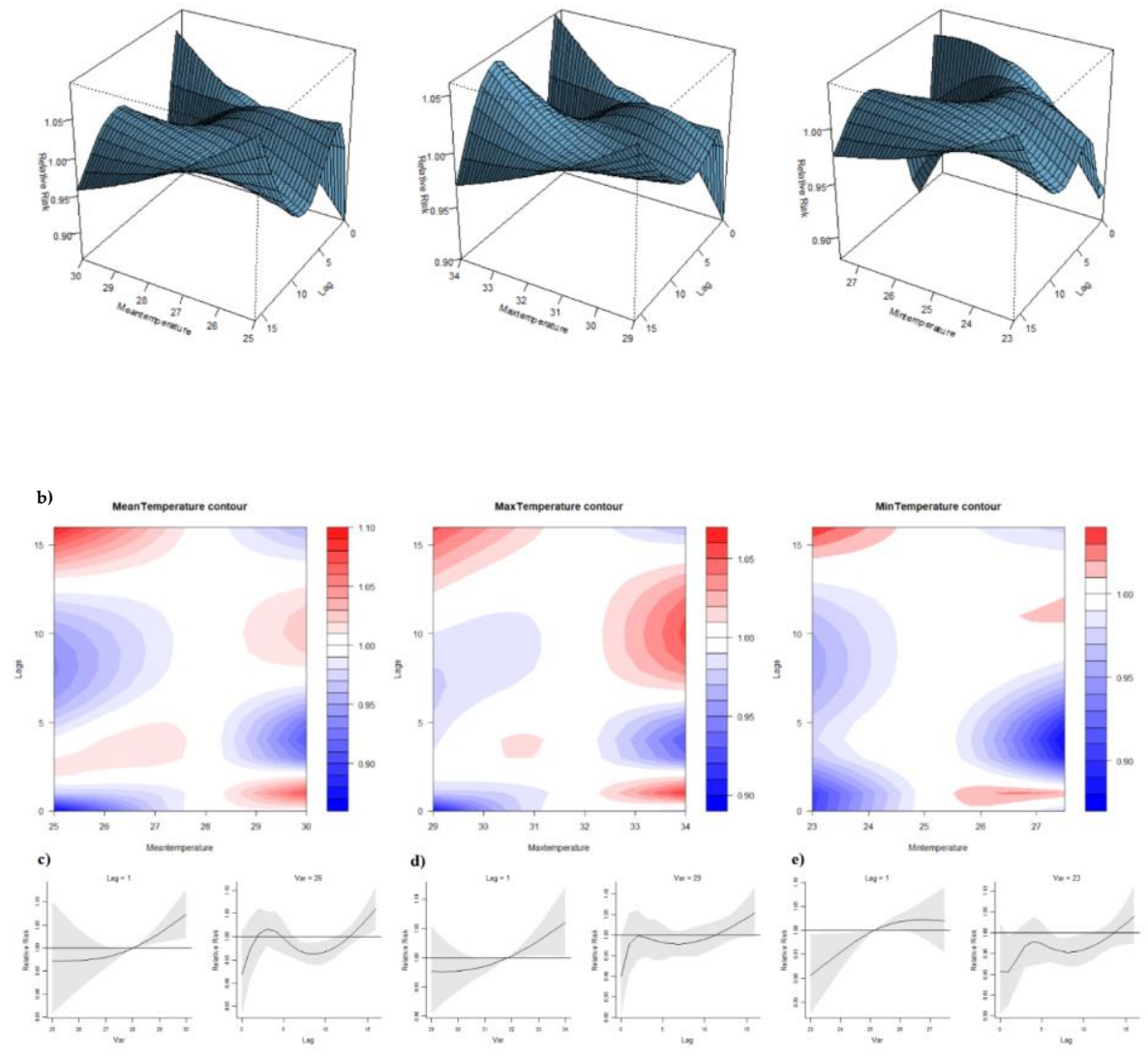

w-
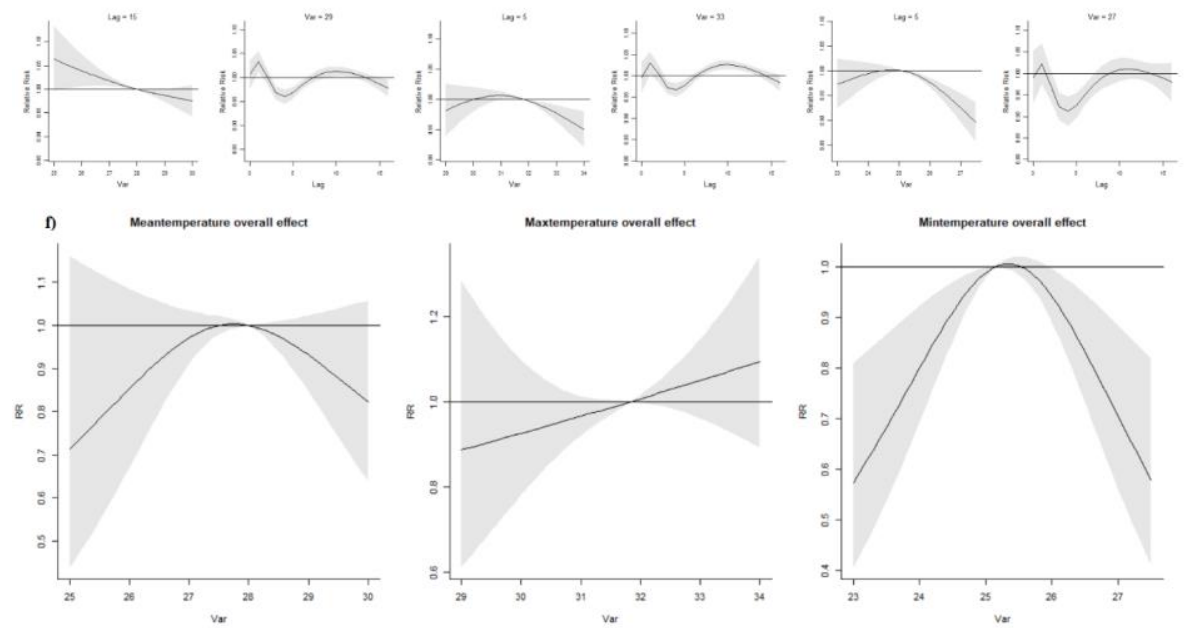

Figure 5. (a) 3D graph of temperature-lag-dengue association; (b) contour graph of temperaturelag-dengue association; (c) sliced graph of mean temperature/lag-dengue association (notes: left top panel shows temperature-dengue association at lag 1 while left bottom one at lag 5; right top panel shows lag-dengue association at mean temperature $26{ }^{\circ} \mathrm{C}$ while right bottom one at mean temperature $29^{\circ} \mathrm{C}$; (d) sliced graph of max temperature/lag-dengue association (Notes: left top panel shows max temperature-dengue association at lag 1 while left bottom one at lag 5 ; right top panel shows lag-dengue association at max temperature $29^{\circ} \mathrm{C}$ while right bottom one at max temperature $33{ }^{\circ} \mathrm{C}$ ); (e) sliced graph of min temperature/lag-dengue association (Notes: left top panel shows min temperature-dengue association at lag 1 while left bottom one at lag 5; right top panel shows lag-dengue association at min temperature $23^{\circ} \mathrm{C}$ while right bottom one at min temperature $27^{\circ} \mathrm{C}$ ); (f) overall effect graph of mean temperature-dengue association. 


\subsubsection{Effect of Wind Speed}

The reference value of wind speed was $7.52 \mathrm{~km} / \mathrm{h}$. Different associations between wind speed and dengue were observed at marginal lags and middle lags, as displayed by the 3D and contour graphs of wind speed-lag-dengue association (Figure $6 \mathrm{a}, \mathrm{b}$ ). Meanwhile, high and low wind speeds had distinct relationships with RR. When a one-week lag was considered (Figure 6c), RR increased when wind speed ranged around $5-7.52 \mathrm{~km} / \mathrm{h}$ and remained constant with a further increase in wind speed. When a 5-week lag effect was factored in, higher wind speed clearly reduced the RR of dengue. A higher wind speed at $9 \mathrm{~km} / \mathrm{h}$ exhibited a negative effect on RR along with the lags compared to $6 \mathrm{~km} / \mathrm{h}$. Overall, the wind speed was associated with decreasing RR (Figure 6d), with a wind speed of $13 \mathrm{~km} / \mathrm{h}$ associated with an overall reduction in risk of dengue (RR: $0.70,95 \%$ CI: $0.57,0.87$ ) compared to the reference.

a)

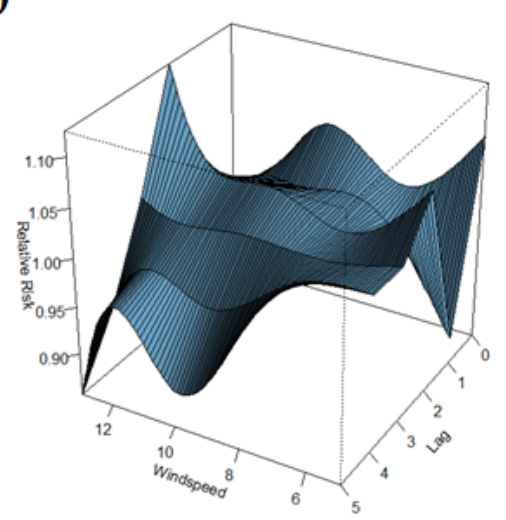

b)

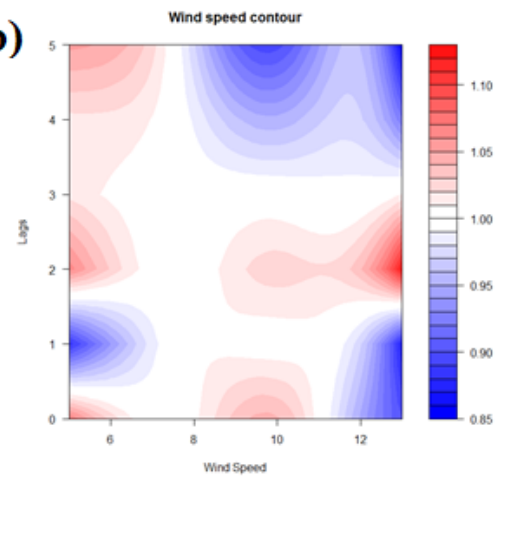

c)
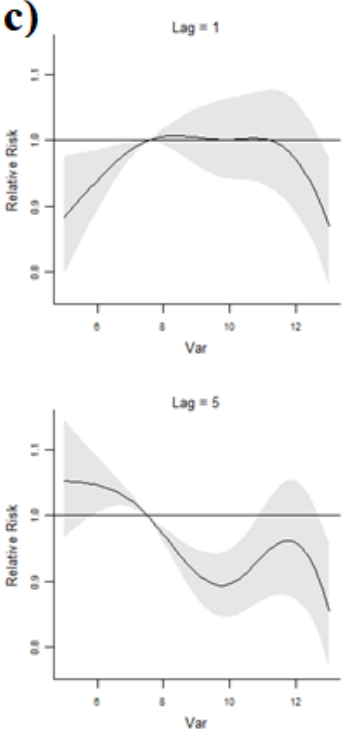
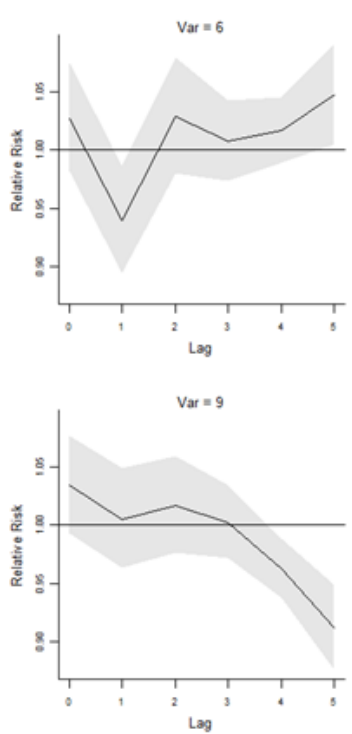

d)

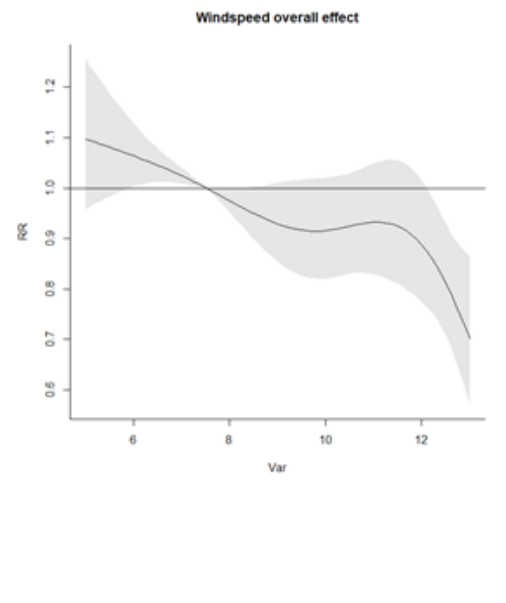

Figure 6. (a) 3D graph of wind speed-lag-dengue association; (b) contour graph of wind speed-lagdengue association; (c) sliced graph of wind speed/lag-dengue association (Notes: left top panel shows wind speed-dengue association at lag 2 while the left bottom one at lag 5; right top panel shows a lag-dengue association at wind speed $6 \mathrm{~km} / \mathrm{h}$ while the right bottom one at wind speed $10 \mathrm{~km} / \mathrm{h}$ ); (d) overall effect graph of wind speed-dengue association.

\subsubsection{Sensitivity Analysis}

In general, varying the degree of freedom (df) of time trend and seasonality did not change the direction of effect to a large degree (Figure S12). However, some statistical significance was lost when df per year increased, such as PSI around 100. The general 
features of overall effect in Figure S13 remained the same when polynomial functions were applied.

\section{Discussion}

This study explored the association between dengue incidence and several weather factors in Singapore between 2012 and 2019, furthering the analysis by $\mathrm{Xu}$ and co-authors, who explored whether factors' impact on dengue in Singapore between 2001 and 2009 [19]. The relationship between weather factors and dengue cases may vary across different periods, especially with increasing global warming and urbanization. Therefore, independent research on these relationships is critical to guide environmental-related policy. Apart from weather variables included in $\mathrm{Xu}$ et al., this study considered PSI as a new indicator that could influence the dengue trend. Hussain-Alkhateeb et al. wrote on the successful deployment of an early warning and response system utilizing mean temperature, rainfall, and humidity in the prediction of dengue outbreaks in Brazil, Mexico, and Malaysia; sensitivity and predictive values ranged from $81-99 \%$ and $50-88 \%$, respectively [41]. However, their study lacked the exploration of wind speed and PSI level. During the process of model fitting, the degree of freedom parameters and the largest number of weeks were estimated independently in each weather-related model instead of using the same settings of parameters in all models.

In this study, the high temperature was found to be negatively associated with dengue transmission. The reference (median) was reflective of the relatively uniform temperatures that Singapore experiences year-round and increases in temperatures may hinder transmission. However, the risk of dengue increases steeply up to $29^{\circ} \mathrm{C}$ and decreases when the temperature is higher than $29^{\circ} \mathrm{C}$. Hence, our study's results seem to support the idea of an optimum temperature range that promotes dengue transmission, and temperatures outside this range prevent dengue transmission. While we studied the influence of various temperature types on dengue incidence, it is important to note that minimum temperature has proven to be more apt than the other temperature measures due to its consistent significant association with dengue RR (Figure 5). On the contrary, a systematic review of temperature's effect on dengue risk found that higher mean, maximum and minimum temperatures were individually associated with increased dengue transmission [42]. Another study looking at dengue patterns in Singapore from 1974 until 2011 found that the higher minimum and mean temperature was related to higher dengue transmission, while maximum temperature had no statistically significant relation [43]. On the other hand, $\mathrm{Xu}$ et al. reported that dengue incidence in Singapore was amplified by mean temperatures above $27.8^{\circ} \mathrm{C}$ (reference value) in 2001-2009, while mean temperatures deviating from $27.8^{\circ} \mathrm{C}$ in 2004-2006 and 2007-2009 were associated with reduced dengue transmission [19]. Together with our findings, this corresponds to Connor et al.'s conclusion that Ae. aegypti is the most active at $28{ }^{\circ} \mathrm{C}$ [44].

Concurrently, molecular studies showed that Ae. aegypti survival and development thrives beyond the $30^{\circ} \mathrm{C}$ range $[45,46]$. Others concluded that the ideal range of survival (88-93\%) through all phases of development occurs between $20-30{ }^{\circ} \mathrm{C}$ [45], including Yang, et al. (2009) who reported $29.2{ }^{\circ} \mathrm{C}$ as the best temperature to produce the most offspring [24]. While less is known for Ae. albopictus comparatively, it has a wider developmental temperature range of $15-35^{\circ} \mathrm{C}$; with its shortest gonotrophic cycle occurring at $30^{\circ} \mathrm{C}$; an optimum developmental zero temperature of $29.7^{\circ} \mathrm{C}$; and can survive longer at lower temperatures [44]. One possible explanation for discrepancies between studies could be the differing effects of temperature on various development stages of mosquitos and the dengue virus, accompanied by the dominant strategy of vector control employed at any specific period.

The overall increased effect of temperature on dengue was captured at a lag of one week while elevated temperatures curtailed dengue cases at a lag of five weeks. The five-week lag effect of temperature could be induced by ecological factors pertaining to the Aedes vector such as the length of the gonotrophic cycle, larval development, and growth 
rate of Aedes mosquitoes. On the other hand, the one-week lag effect of temperature may be a result of behavioral tendencies of Aedes mosquitoes and humans that have repercussions in the shorter term, such as time to blood-feeding or health-seeking behavior after the presentation of symptoms. These associations at specific lag should be emphasized to facilitate warning measures.

The decreased risk of dengue transmission with high wind speeds found in this study was consistent with the results of another study in subtropical city in Guangzhou, China, which reported that wind velocity was inversely associated with dengue incidence in the same month [47]. One potential mechanism that could account for the influence of wind speed is the suppression of mosquitoes' host-seeking flight activity [48], which reduces oviposition and contact with hosts. As suggested by Hoffman et al. (2002), wind may deter plume following in mosquitoes due to their inability to progress upwind or dilute chemical attractants emitted by the host [49]. Since wind speed affects the mobility of adult mosquitoes, the minimal two-week lag between wind speed and dengue RR observed in this study was consistent with the Ae. aegypti's predicted infective life of 18.26 days at a higher temperature of $30.6^{\circ} \mathrm{C}$ by Goindin, et al. [36]. The lag was also aligned with the sum of mean extrinsic and intrinsic incubation periods, which represents the period from the infection of a mosquito to the presentation of symptoms in an infected human, estimated at 6.5 (at $30{ }^{\circ} \mathrm{C}$ ) and 5.9 days, respectively [50]. Alternatively, wind also directly affects the evaporation rate of both outdoor and indoor vector breeding sites [51], reducing the availability of breeding sites and larval productivity.

Our findings indicate that moderate PSI level (defined as 50-100 by NEA) would increase risk of dengue while unhealthy PSI level (defined as 101-200 by NEA) would inhibit dengue. Extremely high PSI values $(>150)$ reduced the number of dengue cases. This was also supported by a study from Malaysia, where a moderate negative correlation was detected between trapped larvae counts and Air Pollution Index (API) with a oneweek lag [52]. Another study conducted in Brazil found particulate matter 10 microns or less (PM10) to have a statistically significant negative correlation with dengue cases [53]. However, a lack of association between dengue activity and haze between 2001 and 2008 were reported from Singapore [24]. It should be noted that the study only utilized the ARIMA model, which explored linear association, whereas this analysis was supplemented with the use of a non-linear quasi-Poisson model. While there is a limited value of this potential association at a policy level to control dengue, this finding still has academic value in strengthening our understanding and prediction of dengue incidence. Smoke, a component of haze, was anecdotally claimed to repel insects from biting [54,55]. The toxicity of haze was believed to reduce mosquito density, as deleterious effect from direct and indirect exposure to haze was found on the development and survival of butterflies [56]. Nonetheless, research pertaining to haze remains sparse. More evidence is required on the mechanisms by which air quality may affect mosquito development or biting habits.

The volume of rainfall has long been viewed as a plausible factor affecting dengue in the domain of public health. Although we spotted some significant intervals showing positive and negative effects alternately across the lags, the conclusion was challenged by variation of CI in a sensitivity analysis. Another study looking at dengue incidence in Singapore from 2000 to 2007 [57] also demonstrated an absence of a relationship between rainfall and dengue incidence $[28,29]$. One possible explanation could be the role of indoor breeding in urban settings, which is sheltered from outdoor elements. The importance of stagnant water as breeding sites is emphasized by anti-dengue campaigns in Singapore compelling citizens to routinely empty water from flower pots/trays, containers, and closed perimeter drains. According to MOH's report on vector surveillance in 2018 [38], the top breeding habitats for Ae. aegypti included domestic containers (32\%), flowerpots/trays $(11.1 \%)$, ornamental containers $(9.3 \%)$ and closed perimeter drains $(3.7 \%)$. On the other hand, a study looking at dengue incidence in Malaysia from 2008-2010 showed that increased bi-weekly accumulated rainfall had a positively strong effect on dengue cases [48]. Yet, experimental and observational studies have shown that excessive rainfall can "flush 
out" breeding sites and destroy developing larvae, which is consistent with our conclusion. At least two other studies in Singapore have also demonstrated that dengue incidence between 2000 and 2016 was significantly reduced following months where flushing events from wet weather were most frequent $[58,59]$. These collectively indicate that a more detailed analysis with the use of flood-prone spatial data and its contribution of indoor mosquito breeding, is required to understand the complex role of rainfall patterns on dengue transmission.

In the sensitivity analysis, the reduction in significance was likely due to the competence of more sophisticated spline function for time trend and seasonality, in another words, the higher collinearity between terms in model result in wider confidence interval of relative risk estimate [59]. From the sensitivity analysis conducted, we note with caution that varying parameters of the climatic variables to marginal values that are not commonly recorded may reduce the statistical significance of RR predicted by the model.

\section{Limitations}

Although some long-term significant lags indicated a weak seasonal pattern, the seasonal period and its potential influence on these climatic factors were not studied further. The generalizability of the model may not be applicable to all tropical countries since the model is contextualized to Singapore's setting. Only short-term predictions can be performed with these results since long-term predictions would be inaccurate and cause larger prediction errors. With climatic variables derived from our quasi-Poisson model, dengue predictions made a week in advance would have moderate performance, as assessed by split-sample model validation. Additionally, this analysis did not include relative humidity and absolute humidity due to the absence of government API data before 2016. In particular, Xu et al. (2014)'s Singapore study concluded that absolute humidity was the most useful weather factor in dengue forecasting.

Moreover, our model did not consider other major factors including circulating dengue serotypes and geospatial differences. In Singapore, the variations of urban housing across its geography, from landed estates to high-rise buildings have been found to influence differences in the dengue distribution [12]. Additionally, weekly meteorological indicators in this analysis were calculated by averaging data across all 63 stations nationwide and do not account for potential geographical differences in weather. Nevertheless, the variation is likely small given the small size of Singapore. Lastly, the study assumes the effectiveness of vector control is constant, regardless of its intensity level, across this period.

\section{Conclusions}

The reduction in risk of dengue transmission was associated with poor air quality, high wind speeds, minimum temperature beyond $27^{\circ} \mathrm{C}$, and excessive rainfall above $12 \mathrm{~mm}$ per week. Future studies incorporating geospatial data would be important to understand the relationship between these weather factors and dengue risk. This may guide public health and environmental policy for dengue control in countries with tropical urban environments.

Supplementary Materials: The following supporting information can be downloaded at: https: / / www.mdpi.com/article/10.3390/ijerph19010339/s1, Figure S1: Prewhitening cross correlation graphs between six weather factors and dengue cases; Figure S2: Acf \& Pacf graphs of differenced time series of weekly dengue cases with logarithm transformation; Figure S3: Residual plots and Ljung-Box tests (Residual Diagnostics): Left panel is $\operatorname{ARIMA}(1,1,0)$ and right panel is $\operatorname{SARIMA}(0,1,1)(0,1,1)_{52}$; Figure S4: Diagnosis of the residual autocorrelation and overdispersion; Figure S5: Prediction model of dengue incidence without weather factors; Figure S6: Prediction model of dengue incidence with PSI only; Figure S7: Prediction model of dengue incidence with rainfall only; Figure S8: Prediction model of dengue incidence with mean temperature only; Figure S9: Prediction model of dengue incidence with maximum temperature only; Figure S10: Prediction model of dengue incidence with minimum temperature only; Figure S11: Prediction model of dengue incidence with wind speed only; Figure S12 (a): Overall effect with variation in $\delta$. $2 \mathrm{df}$ per year (b): Overall effect with variation 
in $\delta$. $3 \mathrm{df}$ per year; Figure S13: Overall effect of 6 weather variables using polynomial functions; Table S1: Epidemiological characteristics of dengue cases in Singapore from 2012-2019; Table S2: Estimated parameters of distributed lag non-linear model; Table S3: Predictive model performance using 2012-2018 data as training data and 2019 data as test data.

Author Contributions: Conceptualization: J.P.; data curation: H.G., J.K.; methodology: H.G.; formal analysis: H.G.; writing-original draft preparation: H.G.; writing-reviewing and editing: H.G., S.G., J.K., J.P.; visualization: H.G. All authors have read and agreed to the published version of the manuscript.

Funding: This research received no external funding.

Institutional Review Board Statement: Not applicable.

Informed Consent Statement: Not applicable.

Data Availability Statement: Data presented in this study are available in this article and its Supplementary Information File.

Acknowledgments: We would like to thank Nicholas Lau for helping to extract publicly available data for this study. We are deeply grateful to NEA for sharing the meteorological data on open source platform.

Conflicts of Interest: The authors declare no conflicting interests.

\section{References}

1. Lee, S.H.; Nam, K.W.; Jeong, J.Y.; Yoo, S.J.; Koh, Y.-S.; Lee, S.; Heo, S.T.; Seong, S.-Y.; Lee, K.H. The effects of climate change and globalization on mosquito vectors: Evidence from Jeju Island, South Korea on the potential for Asian tiger mosquito (Aedes albopictus) influxes and survival from Vietnam rather than Japan. PLoS ONE 2013, 8, e68512.

2. Simo, F.B.N.; Bigna, J.J.; Kenmoe, S.; Ndangang, M.S.; Temfack, E.; Moundipa, P.F.; Demanou, M. Dengue virus infection in people residing in Africa: A systematic review and meta-analysis of prevalence studies. Sci. Rep. 2019, 9, 13626. [CrossRef]

3. Wilder-Smith, A.; Murray, N.E.A.; Quam, M.B. Epidemiology of dengue: Past, present and future prospects. Clin. Epidemiol. 2013, 5, 299-309. [CrossRef] [PubMed]

4. Changal, K.H.; Raina, A.H.; Raina, A.; Raina, M.; Bashir, R.; Latief, M.; Mir, T.; Changal, Q.H. Differentiating secondary from primary dengue using IgG to IgM ratio in early dengue: An observational hospital based clinico-serological study from North India. BMC Infect. Dis. 2016, 16, 715. [CrossRef] [PubMed]

5. Junxiong, P.; Yee-Sin, L. Clustering, climate and dengue transmission. Expert Rev. Anti-Infect. Ther. 2015, 13, 731-740. [CrossRef]

6. Hii, Y.L.; Zaki, R.A.; Aghamohammadi, N.; Rocklöv, J. Research on Climate and Dengue in Malaysia: A Systematic Review. Curr. Environ. Health Rep. 2016, 3, 81-90. [CrossRef] [PubMed]

7. Rajarethinam, J.; Ang, L.W.; Ong, J.; Ycasas, J.; Hapuarachchi, H.C.; Yap, G.; Chong, C.-S.; Lai, Y.-L.; Cutter, J.; Ho, D.; et al. Dengue in Singapore from 2004 to 2016: Cyclical Epidemic Patterns Dominated by Serotypes 1 and 2. Am. J. Trop. Med. Hyg. 2018, 99, 204-210. [CrossRef] [PubMed]

8. Koh, B.K.W.; Ng, L.C.; Kita, Y.; Tang, C.S.; Ang, L.W.; Wong, K.Y.; James, L.; Goh, K.T. The 2005 dengue epidemic in Singapore: Epidemiology, prevention and control. Ann. Acad. Med. Singap. 2008, 37, 538-545. [PubMed]

9. Ooi, E.-E.; Goh, K.-T.; Gubler, D.J. Dengue prevention and 35 years of vector control in Singapore. Emerg. Infect. Dis. 2006, 12, 887-893. [CrossRef]

10. Fan, J.-C.; Liu, Q.-Y. Potential impacts of climate change on dengue fever distribution using RCP scenarios in China. Adv. Clim. Chang. Res. 2019, 10, 1-8. [CrossRef]

11. Hii, Y.L.; Rocklöv, J.; Ng, N.; Tang, C.S.; Pang, F.Y.; Sauerborn, R. Climate variability and increase in intensity and magnitude of dengue incidence in Singapore. Glob. Health Action 2009, 2, 2036. [CrossRef]

12. Seidahmed, O.M.E.; Lu, D.; Chong, C.-S.; Deng, L.; Eltahir, E.A.B. Patterns of Urban Housing Shape Dengue Distribution in Singapore at Neighborhood and Country Scales. GeoHealth 2018, 2, 54-67. [CrossRef] [PubMed]

13. Christophers, S. Aëdes aegypti (L.) the Yellow Fever Mosquito: Its Life History, Bionomics and Structure; The Syndics of the Cambridge University Press: London, UK, 1960. (In English)

14. Ngugi, H.N.; Mutuku, F.M.; Ndenga, B.A.; Musunzaji, P.S.; Mbakaya, J.O.; Aswani, P.; Irungu, L.W.; Mukoko, D.; Vulule, J.; Kitron, U.; et al. Characterization and productivity profiles of Aedes aegypti (L.) breeding habitats across rural and urban landscapes in western and coastal Kenya. Parasites Vectors 2017, 10, 1-12. [CrossRef]

15. Wongkoon, S.; Jaroensutasinee, M.; Jaroensutasinee, K.; Preechaporn, W. Development sites of Aedes aegypti and Ae. albopictus in Nakhon Si Thammarat, Thailand. WHO Dengue Bull. 2007, 31, 141-152.

16. Morin, C.W.; Comrie, A.C.; Ernst, K. Climate and dengue transmission: Evidence and implications. Environ. Health Perspect. 2013, 121, 1264-1272. [CrossRef] [PubMed] 
17. Lai, Y.-H. The climatic factors affecting dengue fever outbreaks in southern Taiwan: An application of symbolic data analysis. Biomed. Eng. Online 2018, 17, 148. [CrossRef]

18. Ebi, K.L.; Nealon, J. Dengue in a changing climate. Environ. Res. 2016, 151, 115-123. [CrossRef]

19. Xu, H.-Y.; Fu, X.; Lee, L.K.H.; Ma, S.; Goh, K.T.; Wong, J.; Habibullah, M.S.; Lee, G.K.K.; Lim, T.K.; Tambyah, P.A.; et al. Statistical Modeling Reveals the Effect of Absolute Humidity on Dengue in Singapore. PLoS Negl. Trop. Dis. 2014, 8, e2805. [CrossRef]

20. Thu, H.M.; Aye, K.M.; Thein, S. The effect of temperature and humidity on dengue virus propagation in Aedes aegypti mosquitos. Southeast Asian J. Trop. Med. Public Health 1998, 29, 280-284.

21. Aziz, A.T.; Dieng, H.; Ahmad, A.H.; A Mahyoub, J.; Turkistani, A.M.; Mesed, H.; Koshike, S.; Satho, T.; Salmah, C.; Ahmad, H.; et al. Household survey of container-breeding mosquitoes and climatic factors influencing the prevalence of Aedes aegypti (Diptera: Culicidae) in Makkah City, Saudi Arabia. Asian Pac. J. Trop. Biomed. 2012, 2, 849-857. [CrossRef]

22. Schmidt, W.-P.; Suzuki, M.; Thiem, V.D.; White, R.G.; Tsuzuki, A.; Yoshida, L.-M.; Yanai, H.; Haque, U.; Tho, L.H.; Anh, D.D.; et al Population Density, Water Supply, and the Risk of Dengue Fever in Vietnam: Cohort Study and Spatial Analysis. PLoS Med. 2011, 8, e1001082. [CrossRef]

23. Naish, S.; Dale, P.; Mackenzie, J.S.; McBride, J.; Mengersen, K.; Tong, S. Climate change and dengue: A critical and systematic review of quantitative modelling approaches. BMC Infect. Dis. 2014, 14, 167. [CrossRef]

24. Wilder-Smith, A.; Earnest, A.; Tan, S.B.; Ooi, E.E.; Gubler, D.J. Lack of association of dengue activity with haze. Epidemiol. Infect. 2010, 138, 962-967. [CrossRef] [PubMed]

25. Hapuarachchi, H.C.; Koo, C.; Rajarethinam, J.; Chong, C.-S.; Lin, C.; Yap, G.; Liu, L.; Lai, Y.-L.; Ooi, P.L.; Cutter, J.; et al. Epidemic resurgence of dengue fever in Singapore in 2013-2014: A virological and entomological perspective. BMC Infect. Dis. 2016, 16, 300. [CrossRef] [PubMed]

26. Sen, N.J. Dengue Cases at Four-Year High Today Online. 2020. Available online: https://www.todayonline.com/singapore/ dengue-cases-four-year-high (accessed on 7 October 2020).

27. Chew, M.F. Forum: Dengue Control Measures Have Significantly Reduced Transmissions The Straits Times. 2020. Available online: https:/ / www.straitstimes.com/forum/dengue-control-measures-have-significantly-reduced-transmissions (accessed on 7 October 2020).

28. Ministry of Health. Weekly Infectious Diseases Bulletin: Ministry of Health. Available online: https://www.moh.gov.sg/ resources-statistics/infectious-disease-statistics/2020/weekly-infectious-diseases-bulletin (accessed on 7 October 2020).

29. Agency, N.E. Historical Daily Records: National Environment Agency. 2020. Available online: http://www.weather.gov.sg/ climate-historical-daily (accessed on 7 October 2020).

30. Singapore Department of Statistics. Population and Population Structure: Department of Statistics, Singapore. 2020. Available online: https:/ / www.singstat.gov.sg/find-data/search-by-theme/population/population-and-population-structure/latest-data (accessed on 7 October 2020).

31. Bayazit, M.; Önöz, B. To prewhiten or not to prewhiten in trend analysis? Hydrol. Sci. J. 2007, 52, 611-624. [CrossRef]

32. Gasparrini, A.; Armstrong, B.; Kenward, M.G. Distributed lag non-linear models. Stat. Med. 2010, 29, 2224-2234. [CrossRef]

33. Gasparrini, A. Modeling exposure-lag-response associations with distributed lag non-linear models. Stat. Med. 2014, 33, 881-899. [CrossRef]

34. Berk, R.; MacDonald, J. Overdispersion and Poisson Regression. J. Quant. Criminol. 2008, 24, 269-284. [CrossRef]

35. Lopes, T.F.; Holcman, M.M.; Barbosa, G.; Domingos, M.D.F.; Barreiros, R.M.O.V. Laboratory evaluation of the development of Aedes aegypti in two seasons: Influence of different places and different densities. Rev. Inst. Med. Trop. Sao Paulo 2014, 56, 369-374. [CrossRef] [PubMed]

36. Goindin, D.; Delannay, C.; Ramdini, C.; Gustave, J.; Fouque, F. Parity and longevity of Aedes aegypti according to temperatures in controlled conditions and consequences on dengue transmission risks. PLoS ONE 2015, 10, e0135489. [CrossRef]

37. Gasparrini, A. Distributed Lag Linear and Non-Linear Models in R: The Package dlnm. J. Stat. Softw. 2011, 43, 1-20. [CrossRef] [PubMed]

38. Health, M. Communicable Diseases Surveillance in Singapore. Available online: https://www.moh.gov.sg/resources-statistics (accessed on 7 October 2020).

39. Times, T.S. Dengue Cases up Again after Five Weeks of Decline: The Straits Times. 2020. Available online: https://www straitstimes.com/singapore/dengue-cases-up-again-after-five-weeks-of-decline (accessed on 7 October 2020).

40. Asia, C.N. Dengue Cases Expected to Exceed 16,000 Cases unless Immediate Action Taken: NEA: Channel News Asia. 2020. Available online: https:/ /www.channelnewsasia.com/news/singapore/dengue-cases-expected-exceed-16000-nea-12659668 (accessed on 7 October 2020).

41. Hussain-Alkhateeb, L.; Kroeger, A.; Olliaro, P.; Rocklöv, J.; Sewe, M.O.; Tejeda, G.; Benitez, D.; Gill, B.; Hakim, S.L.; Carvalho, R.G.; et al. Early warning and response system (EWARS) for dengue outbreaks: Recent advancements towards widespread applications in critical settings. PLOS ONE 2018, 13, e0196811.

42. Fan, J.; Wei, W.; Bai, Z.; Fan, C.; Li, S.; Liu, Q.; Yang, K. A systematic review and meta-analysis of dengue risk with temperature change. Int. J. Environ. Res. Public Health 2015, 12, 1-15. [CrossRef]

43. Struchiner, C.; Rocklöv, J.; Wilder-Smith, A.; Massad, E. Increasing dengue incidence in Singapore over the past 40 years: Population growth, climate and mobility. PLoS ONE 2015, 10, e0136286. [CrossRef] 
44. Reinhold, J.M.; Lazzari, C.R.; Lahondère, C. Effects of the Environmental Temperature on Aedes aegypti and Aedes albopictus Mosquitoes: A Review. Insects 2018, 9, 158. [CrossRef] [PubMed]

45. Rueda, L.M.; Patel, K.J.; Axtell, R.C.; Stinner, R.E. Temperature-dependent development and survival rates of Culex quinquefasciatus and Aedes aegypti (Diptera: Culicidae). J. Med. Entomol. 1990, 27, 892-898. [CrossRef] [PubMed]

46. Marinho, R.A.; Beserra, E.B.; Bezerra-Gusmão, M.A.; Porto, V.D.S.; Olinda, R.A.; dos Santos, C.A.C. Effects of temperature on the life cycle, expansion, and dispersion of Aedes aegypti (Diptera: Culicidae) in three cities in Paraiba, Brazil. J. Vector Ecol. 2016, 41, 1-10. [CrossRef]

47. Lu, L.; Lin, H.; Tian, L.; Yang, W.; Sun, J.; Liu, Q. Time series analysis of dengue fever and weather in Guangzhou, China. BMC Public Health 2009, 9, 395. [CrossRef]

48. Cheong, Y.L.; Burkart, K.; Leitão, P.J.; Lakes, T. Assessing weather effects on dengue disease in Malaysia. Int. J. Environ. Res. Public Health 2013, 10, 6319-6334. [CrossRef]

49. Hoffmann, E.J.; Miller, J.R. Reduction of Mosquito (Diptera: Culicidae) Attacks on a Human Subject by Combination of Wind and Vapor-Phase DEET Repellent. J. Med. Entomol. 2002, 39, 935-938. [CrossRef]

50. Chan, M.; Johansson, M.A. The Incubation Periods of Dengue Viruses. PLoS ONE 2012, 7, e50972.

51. Ehelepola, N.D.B.; Ariyaratne, K.; Buddhadasa, W.M.N.P.; Ratnayake, S.; Wickramasinghe, M. A study of the correlation between dengue and weather in Kandy City, Sri Lanka (2003-2012) and lessons learned. Infect. Dis. Poverty 2015, 4, 42. [CrossRef] [PubMed]

52. Ahmad, R.; Suzilah, I.; Najdah, W.M.A.W.; Topek, O.; Mustafakamal, I.; Lee, H.L. Factors determining dengue outbreak in Malaysia. PLoS ONE 2018, 13, e0193326.

53. Carneiro, M.A.F.; Alves, B.D.C.A.; Gehrke, F.D.S.; Domingues, J.N.; Sá, N.; Paixão, S.; Figueiredo, J.; Ferreira, A.; Almeida, C.; Machi, A.; et al. Environmental factors can influence dengue reported cases. Rev. Assoc. Med. Bras. 2017, 63, 957-961. [CrossRef] [PubMed]

54. Vernède, R.; Van Meer, M.M.; Alpers, M.P. Smoke as a form of personal protection against mosquitos, a field study in Papua New Guinea. Southeast Asian J. Trop. Med. Public Health 1994, 25, 771-775. [PubMed]

55. Biran, A.; Smith, L.; Lines, J.; Ensink, J.; Cameron, M. Smoke and malaria: Are interventions to reduce exposure to indoor air pollution likely to increase exposure to mosquitoes? Trans. R Soc. Trop. Med. Hyg. 2007, 101, 1065-1071. [CrossRef]

56. Tan, Y.Q.; Dion, E.; Monteiro, A. Haze smoke impacts survival and development of butterflies. Sci. Rep. 2018, 8, 15667. [CrossRef]

57. Pinto, E.; Coelho, M.; Olívêr, L.; Massad, E. The influence of climate variables on dengue in Singapore. Int. J. Environ. Health Res. 2011, 21, 415-426. [CrossRef]

58. Seidahmed, O.M.E.; Eltahir, E.A.B. A Sequence of Flushing and Drying of Breeding Habitats of Aedes aegypti (L.) Prior to the Low Dengue Season in Singapore. PLoS Negl. Trop. Dis. 2016, 10, e0004842. [CrossRef]

59. Benedum, C.M.; Seidahmed, O.M.E.; Eltahir, E.A.B.; Markuzon, N. Statistical modeling of the effect of rainfall flushing on dengue transmission in Singapore. PLoS Negl. Trop. Dis. 2018, 12, e0006935. [CrossRef] 